IRA International Journal of Management \& Social Sciences ISSN 2455-2267

Vol. 14, Issue 02 (Special Issue) pg. 157-160.

International Conference on Wellbeing: Lifespan Perspectives छo Practices for Sustainable

Communities, 2019.

\title{
Resilience and Emotional Intelligence: A Comparative Study between Government and Private School Children in Sonapur, Assam
}

Dr. Sabiha Alam Choudhury ${ }^{1} \&$ Dr. Riju Sharma ${ }^{2}$

${ }^{1}$ Assistant Professor, Department of Psychology and Counselling, Assam Don Bosco University, India.

${ }^{2}$ Director, School of Humanities and Social Sciences, Assam Don Bosco University, India.

DOI: $10.21013 /$ jmss.v14.n2sp.p15

(C) Authors.

Type of Review: Peer Reviewed under the Responsibility of the conference's Scientific Committee.

Disclaimer: The copyright to this work is retained by the authorship. This work contains the opinions 6 views of the authorship solely and the same are not the views or opinions of the IRA. IRA disclaims of any harm or loss caused due to the published content to any party. 


\begin{abstract}
Resilience can be defined as an individual's capacity to navigate their ways to resources that help to sustain well being. Resilience is the ability to steer through serious life challenges and find ways to bounce back and to thrive. Emotional Intelligence is a dimension that addresses self-regulatory processes of emotions that enable one to make adjustments to achieve individual and group goals; Emotional Intelligence is strongly correlated with individual advancement and success in an academic setting and with a child's academic performance. Teaching resilience to children is utmost essential to help them prepare for challenges. It is a character trait which can help them build self-awareness and self-advocacy skills. It can also help them develop new strategies and tools for solving problems and boost their motivation and self-esteem. Taking into consideration the relevance of both of these variables in the academic life of students, the present study is undertaken to assess the level of resilience and emotional intelligence among the school students of Government and private schools of Sonapur area of Assam.
\end{abstract}

Keywords: Resilience, Emotional Intelligence, School students, Government and private schools

\title{
Introduction:
}

In recent years' studies and research on children and childhood have gained prominence, leading to re conceptualization of childhood where the agency of the child leads to a sense of themselves - as individuals. The adoption of the United Nations Convention on the Rights of the Child is a milestone that has brought about a transformation in the way children were viewed - not as mere objects of charity but as individuals with an identity of their own. It was realized that to make children our future, it is important to make them our today by investing in their physical, social, psychological, spiritual and emotional wellbeing. Gradually efforts were concentrated in creating an ecosystem that incorporates the interconnectedness of individual attributes and the external environment which facilitate in shaping young mind for a healthy society.

Next to the institution of family, the school plays a major role towards building holistic development of children. In this age of globalization and consumerism, children are highly vulnerable and are exposed to great risk of abuse, neglect, bullying, exploitation and stress. In this backdrop it is pertinent that we equip and capacitate our children in a way that they strengthen their coping mechanism and blend, adjust and integrate themselves to contextual realities and challenges. Resilience help cope with adverse life situations and promoting and building resilience in children go a long way in creating a healthy society.

In the face of tragedies, natural disasters, health problems, relationships, work or school problems, resilience is how well a person can adapt to life's events. A person with good resilience can recover faster and with less stress than a person with low resilience.

Everyone has robustness. It's just about how much and how well you use it in your life. Resilience does not mean that the person does not feel the intensity or problem of the event. Rather, it simply means that they have found a pretty good way to deal with it faster than others.

Everyone can learn how to make them more resilient. Like any human ability, learning more resilience can be done at any age, from any background, regardless of your education or family relationships. All you need to do is have willingness to increase your resilience.

After every violent classroom episode in every school or student suicide-all too common today-resilience in schools is talked about. Why do some students rebound from adversity and others not? Resilience is to cope with and function well despite adversity or trauma. Schools have started recognizing the importance of students ' social and emotional well - being and a supportive school climate to promote positive academic and behavioral results more generally. Similarly Emotional intelligence is an extremely important tool for solving certain problems relating to school activities and interpersonal relations. Emotional intelligence involves being aware of emotions that affect and interact with traditional intelligence. Emotional intelligence refers to an ability to recognize the meanings of emotion. The development of emotional intelligence becomes an educational objective beginning in children's earliest ages. The interest in self - knowledge and the positive attitude towards oneself and others, as well as the adequate expression of their emotions when interacting with children and adults they know, are general skills that include emotional intelligence. Emotional Intelligence is strongly correlated with individual advancement and success in an academic setting and with a child's academic performance. Taking into consideration the relevance of both of these variables in the academic life of students, the present study is undertaken to assess the level of resilience and emotional intelligence among the school students of Government and private schools of Sonapur area of Assam. 


\section{Objectives of the Study:}

1. To assess the resilience level of the Government and private school students of Sonapur

2. To assess the emotional intelligence level of the Government and private school students of Sonapur

3. To compare the level of resilience between the Government and private school students of Sonapur area

4. To compare the level of emotional intelligence between the Government and private school students of Sonapur area

5. METHOD OF THE STUDY

6. In this research Descriptive Survey Method was used.

7. METHOD OF THE STUDY

8. In this research Descriptive Survey Method was used.

9. METHOD OF THE STUDY

10. In this research Descriptive Survey Method was used.

\section{Sample:}

A total of 200 school children, 100 from private schools and 100 from Government schools in the age group of 5-11 years were selected using purposive sampling technique from four schools in Sonapur area of Guwahati.

\section{Methodology}

In order to collect data the survey method was used. The sample of the study consisted of 200 students (100 from private and 100 from Government schools) of Sonapur area of Guwahati, Assam.

Tools used in the study:

1. The Connon-Davidson Resilience Scale [15] briefer version i.e. the 10 item version (score range 040) was selected. The scale consisted of 10 items to measure the ability to cope with adversity. The scores ranged from 0 (not true at all) to 4 (true nearly all the time) higher scores reflecting greater resilience

2. The Schutte Self Report Emotional Intelligence Test (SSEIT) is a 33 item self-report measure of emotional intelligence developed by Schutte et al. (1998). The SREIS has been designed to map onto the Salovey and Mayer (1990) model of EI. The 33-item survey takes approximately 10 minutes to complete, using a five-point Likert scale, extending from 1 ("strongly disagree") to 5 ("strongly agree"). The total scales scores are computed by reverse coding items 5, 28 and 33 and then making a final summation of all items. High scores on all items collectively indicate high levels of EI (Alston, 2009). Items of the test relate to the three aspects of EI:

(1) appraisal and expression of emotion

(2) regulation of emotion

(3) utilisation of emotion

\section{Results:}

Table 1: Level of Resilience

\begin{tabular}{|l|l|l|l|}
\hline \multirow{2}{*}{ Type of schools } & \multicolumn{2}{|l|}{ Type of Resilience } & Moderate(\%) \\
\cline { 2 - 4 } & High(\%) & Low $(\%)$ & 34 \\
\hline Government & 40 & 26 & 32 \\
\hline Private & 20 & 48 & \\
\hline & & & \\
\hline
\end{tabular}

From the above table it can be seen that in the Government schools, majority of the students had high level of resilience (40\%), and only $26 \%$ of the students were low on resilience. Whereas in the private schools, $48 \%$ of the students were high on the lower dimension of resilience and only $20 \%$ had obtained high resilience

Table 2: Comparison of Resilience of the Government and Private school children

\begin{tabular}{|l|l|l|}
\hline Type of school & Mean & t-value \\
\hline Government & 57.92 & $15.67 * *$ \\
\hline Private & 55.10 & \\
\hline \multicolumn{2}{|l|}{$* *_{\text {- Significant at } \mathrm{p}<0.001}$}
\end{tabular}

The t-test was carried out to find a comparison of the Government and private school students on the dimension of resilience. The higher mean in favour of government school students further indicates that they have significantly higher resilience as compared to private school students. The higher level of 
resilience among the government school students could be attributed to their inner strengths and interpersonal skills. The lack of certain facilities and environment in the government school settings, could be a reason which might have helped them to develop maximum strength to face adverse conditions in life, which is why they may be found to be more resilient as compared to the private school students

Table 3: Level of Emotional Intelligence

\begin{tabular}{|l|l|l|l|}
\hline \multirow{2}{*}{ Type of schools } & \multicolumn{4}{|l|}{ Type of Emotional Intelligence } \\
\cline { 2 - 4 } & High $(\%)$ & Low $(\%)$ & Moderate $(\%)$ \\
\hline Government & 33 & 30 & 37 \\
\hline Private & 35 & 33 & 32 \\
\hline
\end{tabular}

From the above table it can be seen that in the Government schools, 33\% of the students were high on the emotional intelligence level and $30 \%$ were on the low emotional intelligence level. On the other hand in the private schools, $35 \%$ of the students obtained high emotional intelligence and $33 \%$ obtained low emotional intelligence.

Table 4: Comparison of Emotional Intelligence of the Government and Private school children

\begin{tabular}{|l|l|l|}
\hline Type of school & Mean & t-value \\
\hline Government & 56.18 & 0.39 \\
\hline Private & 56.68 & \\
\hline
\end{tabular}

$$
\text { S** - Significant at.01 level }
$$

From the above table it can be seen that there was no significant difference found in between the Government and private school students in the dimension of emotional intelligence.

\section{Conclusion:}

Thus the study shows that students from Government schools are higher in the level of resilience than the students of private schools and also there is significant difference in comparison of their level of resilience. On the other hand, in the dimension of emotional intelligence, the students of private schools were found to be on the higher side than the students of government schools, but there is no significant difference in the comparison of emotional intelligence between the students of both the school types. Although it was seen that in case of the Government schools, the resilience level is higher as compared to the private schools, but when compared in the dimension of emotional intelligence not any of the school types obtained on the higher dimension of emotional intelligence. Emotional intelligence is a very important criterion for the overall development of a child as a high level of emotional intelligence helps children use feelings to identify and solve challenges, communicate with others, and make decisions. Students who lack emotional intelligence can become less connected to school, negatively affecting performance in the classroom, which in turn can reduce their inner strength, confidence and resilience. Therefore it can be considered as a prime duty of schools, both Government and private to build resilience and emotional intelligence in children through a supportive school culture and motivating environment

\section{References:}

[1]. Avey, J. B., Luthans, F., \& Youssef, C. M. (2010). The Additive Value of Positive Psychological Capital in Predicting Work Attitudes and Behaviors. Journal of Management.

[2]. Barling, J. S., Slater, L., \& Kelloway, L. (2000). Transformational leadership and emotional intelligence: An exploratory study. Leadership and Organization.

[3]. Best, K. M., \& Hauser, S. T (1997). Predicting young adult competencies: Adolescent-era parent and individual influences. Journal of Adolescent Research.

[4]. Block, J., \& Kremen, A. M. (1996). IQ and ego resiliency: Conceptual and empirical connections and separateness. Journal of Personality and Social Psychology.

[5]. Carmeli, A. (2003). The relationship between emotional intelligence and work attitudes, behavior and outcomes: An examination among senior managers. Journal of Managerial Psychology.

[6]. Catterall, J. S. (1998). Risk and resiliency in student transitions to high school. American Journal of Education

[7]. Caruso, D. R., Mayer, J. D., \& Salovey, P. (2002). Emotional intelligence and emotional leadership. In R. M. Riggio, Multiple Intelligences and Leadership.

[8]. Feldman Barrett, L., \& Gross, J. (2001). Emotional intelligence: A process model of emotion representation and regulation. In T. J. Mayne, G. A. Bonnano (Eds.), Emotions: Current issues and future directions.

[9]. Goleman, D. (1995). Emotional intelligence. New York: Bantam. 